\title{
Thermodynamics Properties of 1,1-Carbonyldiimidazole (CDI) and 4- Imidazole Acrylic Acid, Obtained by DSC and Combustion Calorimetry
}

\author{
Jesús Baudelio Campos*, José María del Toro Jauregui, Carmen Salomón, Eulogio Orozco-Guareño \\ Laboratorio de Fisicoquímica-Departamento de Química, Centro Universitario de Ciencias Exactas e \\ Ingenierías, Universidad de Guadalajara, Blvd. Marcelino García Barragán \# 1421, esq. Calzada Olímpica. C.P. \\ 44430, Guadalajara, Jalisco, México.
}

*Corresponding author: Jesús Baudelio Campos, email: jesliocg@hotmail.com, cel: 4491179801

Received April 13 ${ }^{\text {th }}, 2020$; Accepted July $9^{\text {th }}, 2020$.

DOI: http://dx.doi.org/10.29356/jmcs.v64i4.1193

\begin{abstract}
In this work, thermodynamic properties of 1,1-carbonyldiimidazole (CDI) and 4-imidazole acrylic are reported. The melting temperature, the enthalpy of fusion and the heat capacity of the compounds were determined by differential scanning calorimetry. The standard molar energy of combustion of both compounds were determined by static-bomb combustion calorimetry and the standard molar enthalpy of formation in the crystalline phase, at $T=298.15 \mathrm{~K}$, was derived and evaluated for the two imidazole derivatives studied. The energetic influence of the acrylic group on the imidazole ring in each of the properties obtained is analyzed and compared with the existing results in the literature.
\end{abstract}

Keywords: Imidazole; enthalpy of formation; melting point; calorimetry; CDI.

Resumen. Se presentan las propiedades termodinámicas del 1,1-carbonildiimidazol (CDI) y el 4-imidazol acrílico. La temperatura de fusión, la entalpía de fusión y la capacidad calorífica de los compuestos se determinaron mediante calorimetría diferencial de barrido. La energía molar estándar de la combustión de ambos compuestos se determinó mediante calorimetría de combustión en bomba estática y la entalpía de formación en fase cristalina, a $\mathrm{T}=298.15$, fue derivada y evaluada para los dos compuestos derivados del imidazol. La influencia energética del grupo acrílico sobre el anillo de imidazol en cada una de las propiedades obtenidas se analiza y compara con los resultados existentes en la literatura.

Palabras clave: Imidazol; entalpía de formación; punto de fusion; calorimetría; CDI.

\section{Introduction}

N-heterocyclic compounds are important because they have special properties and could be used for the synthesis of different drugs with special biological effects. [1-5] As an example of these compounds are imidazoles, specifically these molecules have pharmaceutical and biological properties such as: antihypertensive, antihistaminic, antibacterial, anthelmintic, antifungal, immunomodulatory and antithyroid [6]. Two compounds of the imidazole family were studied: 1,1-carbonyldiimidazole (CDI) and 4-imidazole acrylic acid or urocanic acid (UCA), their chemical structures are shown in Fig. 1. These compounds are precursors in the synthesis of some intermediates in chemical reactions that contain the imidazole ring. 


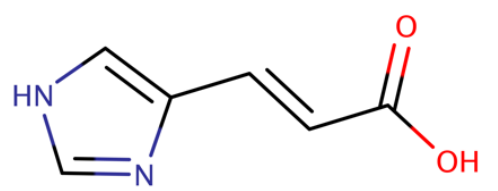

(a)

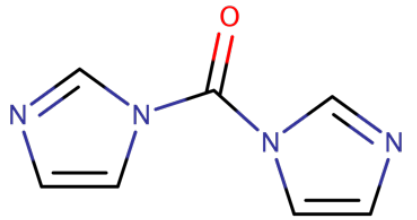

(b)

Fig. 1. Chemical structures of (a) acrylic 4-imidazole acid (UCA) and (b) 1,1-carbonyldiimidazole (CDI).

UCA is formed in the upper layers of the epidermis, where fibrin, a histidine-rich filamentous protein produced after excision of profibrin caspase-14, breaks down into proteinases within the component. UCA is the main predominant species in the stratum corneum and is therefore crucial for the efficient function of the epidermal barrier. [7] Synthetic UCA is used as a sunscreen because it reduces the risk of skin burns from UV rays, [8] therefore it has been of great interest in the field of photobiology. [9,10] On the other hand CDI, $\left(\mathrm{C}_{3} \mathrm{H}_{3} \mathrm{~N}_{2}\right)_{2} \mathrm{CO}$, is frequently used to bind amino acids in peptide synthesis and as a reagent in organic synthesis. [11] In the field of peptide synthesis, this product can be treated with an amino acid or a peptide ester (or amino acid hydrochloride in water) to release the imidazole group and couple the peptides.

Despite the possible biological activities of these compounds, their thermodynamics properties in the crystalline phase and phase transitions are not reported in the literature. Knowledge of these properties provides the suitable conditions for the synthesis of new compounds in which UCA and CDI are involved, and on an industrial scale allows appropriate energy balances to be made.

Thermodynamics properties such as enthalpy of fusion $\left(\Delta_{\text {fus }} H\right)$, melting temperature $\left(T_{\text {fus }}\right)$ and heat capacity $(C p)$ were carried out by differential scanning calorimetry (DSC). The standard molar energy of combustion, $\Delta_{c} U^{\circ}{ }_{m}(\mathrm{cr})$, was determined by combustion calorimetry in a static bomb and finally the standard molar enthalpy of formation in crystalline phase, $\Delta_{f} H_{m}^{\circ}(\mathrm{cr})$, at $T=298.15 \mathrm{~K}$, was derived.

\section{Experimental}

\section{Materials}

The imidazole family compounds studied were supplied by Aldrich, all are solids with purities greater than 0.97 mole fraction according to the supplier's certificate. For UCA purification, HPLC grade methanol was used. The purity of the UCA was determined by high performance liquid chromatography (HPLC), acetonitrile, HPLC grade water, anhydrous potassium monobasic phosphate and anhydrous potassium dibasic phosphate were used as mobile phases.

\section{Purity determinations}

Purity of CDI and UCA was determined by DSC on a Discovery DSC TA Instruments calorimeter, 3$5 \mathrm{mg}$ of sample were placed in a hermetic aluminum capsule, a similar empty capsule was used as a reference. The DSC experiments were performed over the temperature range from $T=(323.15-423.15) \mathrm{K}$ and $T=(443.15-$ $533.15) \mathrm{K}$, for CDI and UCA respectively. The sweeps were carried out at a heating rate of $5 \mathrm{~K} \cdot \mathrm{min}^{-1}$ under a nitrogen flow of $50 \mathrm{~cm}^{3} \cdot \mathrm{min}^{-1}$. Four experiments were performed for each compound. The purity was determined by the fractional fusion method. [12] CDI was purified by seccessive resublimation four times at $T=313.15 \mathrm{~K}$. UCA showed degradation after the fusion (Fig. 2); To verify purity, UCA was analyzed by HPLC. A $250 \mathrm{~mm}$ x $4.6 \mathrm{~mm} \mathrm{C8}$ column Waters ${ }^{\circledR}$ was used. A mixture of acetonitrile: phosphate buffer of $\mathrm{pH} 5$ (85:15 $\mathrm{v} / \mathrm{v}$ ) was used as mobile phase and it was pumped isocratically at a flow rate of $2.5 \mathrm{~mL} \mathrm{~min}^{-1}$ during the analyses. The optimal wavelength for the detection of the analytes with adequate sensitivity and specificity was found at $276 \mathrm{~nm}$. Samples with concentration of $1000 \mathrm{ppm}$ were prepared using HPLC grade ethanol as solvent. The 
injection volume was $10 \mu \mathrm{L}$. [13] The purity was calculated based on the percentage of area, using the Open Lab software based on the Modified Gaussian Polynomial mathematical function $\left(\mathrm{G}_{1} \mathrm{PM}\right)$. UCA was purified by recrystallization with HPLC grade methanol.

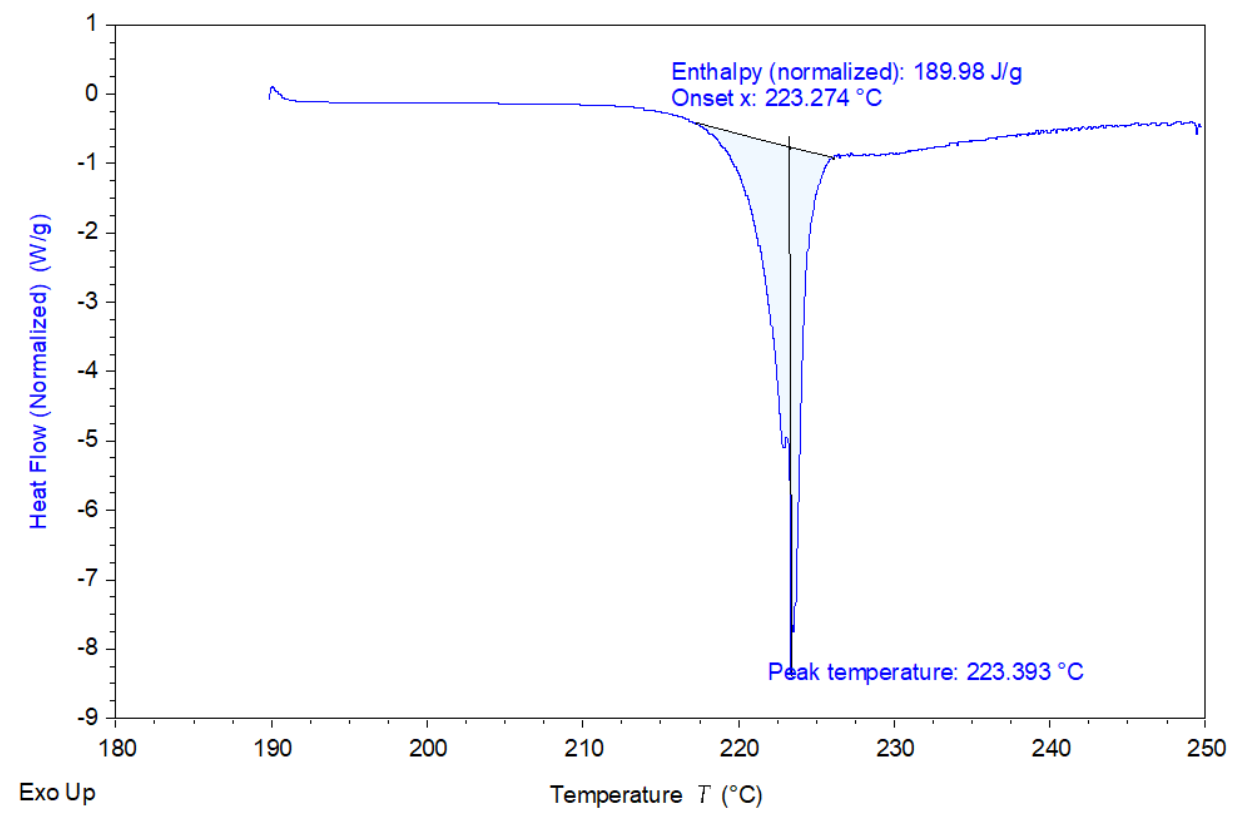

Fig. 2. Thermogram of fusion of UCA.

The purity results $(x)$ are presented in Table 1, which also shows the molecular formulas of the compounds, the method of analysis to determine the purity, and physical properties necessary to perform the calculations for the $\Delta_{c} U_{m(s)}^{\circ}$ as: density $(\rho)$, heat capacity ( $\left.c p\right)$ and the change in internal energy with respect to the pressure at constant temperature $\left(\frac{\partial U}{\partial P}\right)_{T}$.

\section{Determination of melting temperature, enthalpy of fusion and heat capacity by DSC}

The equipment was previously calibrated for temperature and heat flow by analyzing the melting temperature and the enthalpy of fusion of an indium sample, which is a standard material [17] ( $T_{\text {fus }}=429.75 \mathrm{~K}$ and $\left.\Delta_{\text {fus }} H=28.6 \mathrm{~J} \cdot \mathrm{g}^{-1}\right)$. The indium and samples were weighed on a Radwag AS 60/220/C/2 series analytical balance $( \pm 0.01 \mathrm{mg})$.

Before performing any test, dynamic temperature scans from $273.15-630.15 \mathrm{~K}$ at $5 \mathrm{~K} \cdot \mathrm{min}^{-1}$ were completed to observe the performance of the thermal properties of UCA and CDI. The melting enthalpy and temperature were obtained from phase change thermograms achieved in the purity determinations.

The heat capacity of UCA and CDI was determined on the same DSC equipment. $C p$ was previously calibrated using synthetic sapphire as the reference material which heat capacity is $0.775 \mathrm{~J} \mathrm{~g}^{-1} \cdot \mathrm{K}^{-1}$ at $T=298.15$ K. [17] The determination of heat capacity was carry out by means ot the two-step method. [18] Samples from 3 to $5 \mathrm{mg}$ were weighed and put into aluminum capsules. Dynamic temperature sweeps were made from $T=$ 273.15 to $T=343.15 \mathrm{~K}$. A heating rate of $3 \mathrm{~K} \cdot \mathrm{min}^{-1}$ was applied in each experiment under nitrogen flow of 50 $\mathrm{cm}^{3} \cdot \mathrm{min}^{-1}$. The results are shown in Table 1 . 
Table 1. Data and physical properties of the reagents used.

\begin{tabular}{|c|c|c|c|c|c|c|c|c|}
\hline Reagents & Formula & $\mathbf{x}$ & Analysis & CAS No. & $M^{a}$ & $\rho$ & $C p(298.15 \mathrm{~K})$ & $-\left(\frac{\partial U}{\partial P}\right)_{T}$ \\
\hline & & & & & $\mathrm{g} \cdot \mathrm{mol}^{-1}$ & $\mathrm{~g} \cdot \mathrm{cm}^{-3}$ & $\mathrm{~J} \cdot \mathrm{K}^{-1} \cdot \mathrm{g}^{-1}$ & $\mathrm{~J} \cdot \mathrm{g}^{-1} \cdot \mathrm{MPa}^{-1}$ \\
\hline CDI & $\mathrm{C}_{7} \mathrm{H}_{6} \mathrm{~N}_{4} \mathrm{O}$ & 0.9926 & $\mathrm{DSC}$ & $530-62-1$ & 162.15 & 1.10 & 1.4167 & $0.2000^{\mathrm{b}}$ \\
\hline UCA & $\mathrm{C}_{6} \mathrm{H}_{6} \mathrm{~N}_{2} \mathrm{O}_{2}$ & 1.000 & HPLC & $104-98-3$ & 138.124 & 0.87 & 1.1928 & $0.2000^{b}$ \\
\hline Benzoic acid & $\mathrm{C}_{7} \mathrm{H}_{6} \mathrm{O}_{2}$ & 0.999996 & $\begin{array}{c}\text { NIST } \\
\text { certified }\end{array}$ & $65-85-0$ & 122.1209 & $1.32[14]$ & 1.19 [14] & $0.1150[14]$ \\
\hline Cotton thread & $\mathrm{CH}_{1.396} \mathrm{O}_{0.859}$ & N/A & N/A & N/A & 27.1612 & $1.5[14]$ & $1.67[14]$ & $0.2890[14]$ \\
\hline Methanol & $\mathrm{CH}_{3} \mathrm{OH}$ & 0.999 & N/A & $67-56-1$ & N/A & N/A & N/A & N/A \\
\hline Acetonitrile & $\mathrm{C}_{2} \mathrm{H}_{3} \mathrm{~N}$ & 0.999 & N/A & $75-05-8$ & N/A & $\mathrm{N} / \mathrm{A}$ & $\mathrm{N} / \mathrm{A}$ & N/A \\
\hline $\begin{array}{c}\text { Monobasic potassium } \\
\text { phosphate }\end{array}$ & $\mathrm{KH}_{2} \mathrm{PO}_{4}$ & 0.999 & N/A & $7778-77-0$ & $\mathrm{~N} / \mathrm{A}$ & $\mathrm{N} / \mathrm{A}$ & $\mathrm{N} / \mathrm{A}$ & $\mathrm{N} / \mathrm{A}$ \\
\hline $\begin{array}{c}\text { Dibasic Potassium } \\
\text { Phosphate }\end{array}$ & $\mathrm{K}_{2} \mathrm{HPO}_{4}$ & 0.999 & N/A & 7758-11-4 & N/A & N/A & N/A & N/A \\
\hline
\end{tabular}

${ }^{b}$ Recommended value for all organic compounds. [16] 


\section{Combustion calorimetry}

The combustion experiments were performed with an isoperilic calorimeter in a static bomb whose experimental procedure, calibration and all equipment used were described previously by Campos et al. [19] The calorimetric system was calibrated using benzoic acid provided by NIST, having a massic energy of combustion of $(-26434 \pm 3) \mathrm{J} . \mathrm{g}-1$. Seven repetitions were made using aboout $1 \mathrm{~g}$ of benzoic acid in pellet form. The energy equivalent obtained was, $\varepsilon$ (calor) $=(9.7995 \pm 0.0031) \mathrm{kJ} \cdot \mathrm{K}^{-1}$; here the uncertainy corresponds to the standard deviation of the mean. The combustion experiments were carried out in pellet form using a platinum crucible. For all the combustion experiments, the apparent masses of the pellets, the cotton thread, the crucible and platinum wire were measured using a balance (Radwag AS 60/220/C/2 series, accuracy \pm 0.01 $\mathrm{mg}$ ). The apparent mass corrections were also applied. All the combustion experiments were carried out in the presence of $1 \mathrm{~mL}$ of demineralized water and 3.04 MPa of oxygen (mass fraction=0.99999) from Praxair. Five repetitions were performed for each compound. The aqueous phase obtained in the bomb after the combustion experiments of all compounds was collected to quantify the $\mathrm{HNO}_{3}$ formed during the reaction. This solution was transferred to a flask and diluted with distilled water to $50.0 \mathrm{~cm}^{3}$. The amount of $\mathrm{HNO}_{3}$ formed during the reactions was determined by titration with standardized $0.01 \mathrm{M} \mathrm{NaOH}$ (aq). [20] Cotton thread was used as a fuse wire in all the combustions experiments, its empirical formula was determined with a LECO TruSpec micro elemental analyzer. The internal molar energy of cotton was determined experimentaly, $\Delta_{c} U_{m(s)}^{\circ}=-$ $(461.14 \pm 0.60) \mathrm{kJ} \cdot \mathrm{mol}^{-1}$. information.

The details of the combustion experiments of calibration and cotton thread are shown in the supporting

\section{Results and discussion}

\section{Differential Scanning Calorimetry}

Thermal analysis carried out for CDI demonstrates that this type of compound shows thermal degradation at $423.15 \mathrm{~K}$. UCA shows a slight thermal degradation after its fusion, producing a slight change in the baseline, the results obtained for $\Delta_{\text {fus }} H$ and $T_{\text {fus }}$ are shown in Table 2 . The fusion temperature, $T_{\text {fus }}$, for UCA is higher than that of CDI, since the crystalline phase of UCA is more stable.

Table 2. Results of $T_{\text {fus, }}, \Delta_{\text {fus }} H$ and $C_{p}$ obtained by DSC.

\begin{tabular}{|c|c|c|c|c|}
\hline Compound & $\boldsymbol{T}_{\text {fus }}$ & $\Delta_{\text {fus }} \boldsymbol{H}$ & $\boldsymbol{C}_{\boldsymbol{p}}$ & range \\
\hline & $\mathbf{K}$ & $\mathbf{k J} \cdot \mathbf{m o l}^{-1}$ & $\mathbf{J}^{-1} \mathbf{K}^{-1} \mathbf{g}^{-1}$ & $\mathbf{K}$ \\
\hline UCA & $496.4 \pm 1.36$ & $26.49 \pm 1.35$ & $0.655 T-30.529$ & $294.15-338.13$ \\
\hline CDI & $361.95 \pm 0.93$ & $24.80 \pm 0.46$ & $1.26 \mathrm{~T}-145.89$ & $277.15-327.15$ \\
\hline
\end{tabular}

The $C p$ graphs are shown in the supporting information, the equation of this property is shown in Table 2. Considering that there are no degrees of freedom of translation or rotation in the crystal, that the electronic partition functions are reduced to the first term of their serial development and that the nuclear partition function is equal to 1 , then the heat capacity of a crystal falls only in the vibrations of the molecular bonds. Therefore, the results obtained show that the structure of CDI causes a faster temperature rise than UCA.

\section{Combustion calorimetry}

The mean value of the standard molar energy of combustion of the two compounds studied in the crystalline phase, at $T=298.15 \mathrm{~K}$, were obtained from a set of five combustion experiments. From this result the enthalpy of combustion were calculated considering the gaseous moles formed $(\Delta n)$ in the process through Eq 1.

$$
\Delta_{c} H_{m}^{\circ}=\Delta_{c} U_{m}^{\circ}+\Delta n R T
$$


where, $\mathrm{R}$ is the gas constant. The standard molar enthalpy of formation of both compounds in the crystalline phase, $\Delta_{f} H_{m}^{\circ}(c r)$, was determined from the referred to above enthalpy of combustion using $\Delta_{f} H_{m}^{\circ}\left(\mathrm{H}_{2} \mathrm{O}, 1\right)=(-$ $(285.830 \pm 0.042) \mathrm{kJ} \cdot \mathrm{mol}^{-1}$ and $\left(\mathrm{CO}_{2}, \mathrm{~g}\right) \Delta_{f} H_{m}^{\circ}-(393.51 \pm 0.13) \mathrm{kJ} \cdot \mathrm{mol}^{-1},[21]$ according to the equations of the combustion reactions:

$$
\begin{aligned}
& \mathrm{C}_{6} \mathrm{H}_{6} \mathrm{~N}_{2} \mathrm{O}_{2}(\mathrm{cr})+6.5 \mathrm{O}_{2}(g) \rightarrow 6 \mathrm{CO}_{2}(g)+3 \mathrm{H}_{2} \mathrm{O}(\mathrm{l})+\mathrm{N}_{2}(g) \\
& \mathrm{C}_{7} \mathrm{H}_{6} \mathrm{~N}_{4} \mathrm{O}(\mathrm{cr})+8 \mathrm{O}_{2}(g) \rightarrow 7 \mathrm{CO}_{2}(g)+3 \mathrm{H}_{2} \mathrm{O}(\mathrm{g})+2 \mathrm{~N}_{2}(g)
\end{aligned}
$$

The results of $\Delta_{c} U_{m}^{\circ}, \Delta_{c} H_{m}^{\circ}$ and $\Delta_{f} H_{m}^{\circ}(c r)$ are shown in Table 3 . The details of the combustion experiments for CDI and UCA are shown in Table 4.

Table 3. Standard molar energies and enthalpies of combustion and formation of the compounds studied at $T=$

\begin{tabular}{|c|c|c|c|}
\hline & $\begin{array}{c}-\Delta_{c} \mathbf{U}_{m}^{\circ}(s) \\
k J \cdot m o l^{-1}\end{array}$ & $\begin{array}{c}-\Delta_{c} \mathbf{H}^{\circ}{ }_{m}(\mathrm{~s}) \\
\mathrm{kJ} \cdot \mathrm{mol}^{-1}\end{array}$ & $\begin{array}{c}\Delta_{f} \mathbf{H}^{\circ} m(\mathrm{cr}) \\
\mathrm{kJ} \cdot \mathrm{mol}^{-1}\end{array}$ \\
\hline CDI & $4274.27 \pm 0.12$ & $4271.14 \pm 0.15$ & $659.08+0.48$ \\
\hline $\mathrm{UCA}$ & $2857.54+0.14$ & $2856.30 \pm 0.14$ & $-362.25 \pm 0.20$ \\
\hline
\end{tabular}
$298.15 \mathrm{~K}$ and $p^{\circ}=0.1 \mathrm{MPa}$.

The results of $\left(\Delta_{c} U^{\circ}\right)$ include a combined standard uncertainty that was calculated from equation (4), where $\sigma\left(\Delta_{c} U^{\circ}\right)$ corresponds to the combined uncertainty of the combustion energy of each compound, the term $a$ refers to the cotton thread data and $\varepsilon$ (calor), to the calorific value of the calorimeter obtained in the calibration. The uncertainty of $\Delta_{c} H_{m}^{\circ}$ and $\Delta_{f} H_{m}^{\circ}$ correspond to the square root of the sum of the squares of the uncertainties involved in the calculation.

$$
\sigma\left(\Delta_{c} U^{\circ}\right)=\sqrt{\left(\Delta_{c} U^{\circ}\right)^{2}\left\{\left(\frac{\sigma\left(\Delta_{c} U^{\circ}\right)}{\Delta_{c} U^{\circ}}\right)^{2}+\left(\frac{\sigma\left(\Delta_{c} U^{\circ} a\right)}{\Delta_{c} U^{\circ} a}\right)^{2}+\left(\frac{\sigma[\varepsilon(\text { calor })]}{\varepsilon(\text { calor })}\right)^{2}\right\}}
$$

According to the energy values and enthalpies of combustion, this property depends on the electronegativity of the atoms in the functional groups, and on the amount of bonds that are broken and formed during the idealized combustion reactions. With this it is possible to explain the greater energy and enthalpy of combustion of CDI with respect to UCA, whose carbonyl functional group has a lower electronegativity.

The enthalpy of formation in crystalline phase is a measure of the intra and intermolecular interactions of a crystalline compound. UCA has $\mathrm{COOH}$ and N-H groups, which probably establish intermolecular hydrogen bonds that are stronger than interactions present between CDI molecules. This is consistent with the melting enthalpy and melting temperature obtained. 
Table 4. Details of the combustion experiments for CDI and UCA.

\begin{tabular}{|c|c|c|c|c|c|c|c|c|c|c|}
\hline & \multicolumn{5}{|c|}{ CDI Combustions } & \multicolumn{5}{|c|}{ UCA Combustions } \\
\hline & 1 & 2 & 3 & 4 & 5 & 1 & 2 & 3 & 4 & 5 \\
\hline$m(\mathrm{cmp}) / \mathrm{g}$ & 0.30625 & 0.30402 & 0.29836 & 0.30554 & 0.30287 & 0.28456 & 0.28988 & 0.28535 & 0.28579 & 0.24764 \\
\hline$m(c t) / g$ & 0.00619 & 0.00622 & 0.00710 & 0.00615 & 0.00724 & 0.00687 & 0.00719 & 0.00696 & 0.0065 & 0.00682 \\
\hline$m(p t) / g$ & 9.83145 & 9.83183 & 9.83203 & 9.83098 & 9.83115 & 9.83913 & 9.83154 & 9.83221 & 9.8305 & 9.83161 \\
\hline$T_{i} / K$ & 296.8649 & 296.1548 & 296.6937 & 296.179 & 296.2315 & 296.4042 & 296.135 & 296.4513 & 296.4286 & 296.5224 \\
\hline$T_{f} / K$ & 297.8325 & 297.1154 & 297.6483 & 297.1444 & 297.1856 & 297.1755 & 296.8992 & 297.217 & 297.2075 & 297.1763 \\
\hline$\Delta T_{\text {corr }} / K$ & 0.1286 & 0.1278 & 0.1355 & 0.1288 & 0.1225 & 0.1496 & 0.1335 & 0.1463 & 0.1586 & 0.1146 \\
\hline$\Delta T_{c} / K$ & 0.8390 & 0.8328 & 0.8191 & 0.8366 & 0.8316 & 0.6218 & 0.6307 & 0.6194 & 0.6203 & 0.5393 \\
\hline$\varepsilon^{i}($ cont $) / k J \cdot K^{-1}$ & 0.0161 & 0.0161 & 0.0161 & 0.0161 & 0.0161 & 0.0160 & 0.016 & 0.016 & 0.016 & 0.0159 \\
\hline$\varepsilon^{f}($ cont $) / k J \cdot K^{-l}$ & 0.0161 & 0.0161 & 0.016 & 0.0161 & 0.0161 & 0.0162 & 0.0161 & 0.0161 & 0.0161 & 0.016 \\
\hline$-\triangle U_{I B P} / k J$ & 8.2315 & 8.1708 & 8.0359 & 8.2079 & 8.1587 & 6.0986 & 6.1865 & 6.0755 & 6.084 & 5.2896 \\
\hline$\Delta U_{d e c}\left(H N O_{3}\right) / k J$ & 0.0495 & 0.0477 & 0.0465 & 0.0467 & 0.0489 & 0.0901 & 0.0627 & 0.0501 & 0.0567 & 0.0477 \\
\hline$\Delta U_{i g n} / k J$ & 0.0042 & 0.0042 & 0.0042 & 0.0042 & 0.0042 & 0.0042 & 0.0042 & 0.0042 & 0.0042 & 0.0042 \\
\hline$\Delta U_{\Sigma} / k J$ & 0.0047 & 0.0047 & 0.0046 & 0.0047 & 0.0047 & 0.0040 & 0.0042 & 0.0041 & 0.0041 & 0.0035 \\
\hline$-m \Delta_{c} U^{\circ}(c t) / k J$ & 0.1051 & 0.1056 & 0.1205 & 0.1044 & 0.1229 & 0.1167 & 0.1221 & 0.1182 & 0.1104 & 0.1158 \\
\hline$-\Delta_{c} U^{\circ}(\mathrm{cmp}) / \mathrm{kJ} \cdot \mathrm{g}^{-1}$ & 26.3580 & 26.3561 & 26.3581 & 26.3535 & 26.3550 & 20.69 & 20.69 & 20.69 & 20.69 & 20.69 \\
\hline$-\Delta_{c} U^{\circ}(\mathrm{cmp}) / \mathrm{kJ} \cdot \mathrm{mol}^{-1}$ & 4273.92 & 4273.61 & 4273.94 & 4273.19 & 4273.43 & 2857.84 & 2857.81 & 2857.32 & 2857.63 & 2857.12 \\
\hline & \multicolumn{5}{|c|}{$-\left(\Delta c U^{\circ}(298.15 \mathrm{~K}) / \mathrm{kJ} \cdot \mathrm{mol}^{-1}\right)=4273.62 \pm 0.15$} & \multicolumn{5}{|c|}{$-\left(\Delta c U^{\circ}(298.15 \mathrm{~K}) / \mathrm{kJ}^{\prime} \mathrm{mol}^{-1}\right)=2857.54 \pm 0.14$} \\
\hline
\end{tabular}

$m(\mathrm{c})$, mass of the compound; $m(\mathrm{ct})$, mass of cotton thread; $m(\mathrm{pt})$, mass of platinum that includes the crucible and ignition wire; Ti, initial temperature; $T f$, final temperature; $\Delta T$ corr , correction term; $\Delta T \mathrm{c}$, corrected temperature rise; $\varepsilon i(\mathrm{cont})$, initial energy equivalent of the bomb; $\varepsilon f($ cont), final energy equivalent of the bomb; $\Delta U$ ign, ignition energy; $\Delta U \mathrm{IBP}$, energy of the isothermal bomb process; $\Delta U \Sigma$, correction to the standard states; and $\Delta c U^{\circ}$, molar energy of combustion (ct and $c m p$ are cotton thread and compound, respectively). [19] 


\section{Conclusions}

Using calorimetric techniques, reliable data were obtained for CDI ans UCA such as: melting temperatures and melting enthalpyies, heat capacity, energy and enthalpy of combustion, and standard molar enthalpy of formation in crystalline phase, at $T=298.15 \mathrm{~K}$ These data are of great contribution to databases of thermodynamic properties. Thermal analysis for CDI and UCA shows degradation for CDI at $T=423.15 \mathrm{~K}$ and after fusion for UCA.

\section{Acknowledgments}

Carmen Salomon thanks CONACyT for it grants (registration numbers: 327677).

\section{References}

1. Wiseman, L.; Lombardino, J. G.; Wiseman, E. H. J. Med. Chem. 1974, 17,1182-1188.

2. Sundberg, R.J.; Martin, R. B. Chem. Rev. 1973,74,471-517.

3. Shalini, K.; Sharma, P. K.; Kumar, N. Chem. Sin. 2010, 1, 36-47.

4. Suvarna, A. S. J. Chem. Sci. 2015, 5, 67-72.

5. Verma, A.; Joshi, S.; Singh, D. J. Chem. 2013, 2013, 1-12.

6. Fortún Abete, J. Medicine (Baltimore) 1998, 7, 133-140.

7. Gibbs, N. K.; Norval, M. Photochem. Photobiol. Sci. 2008, 7, 655-667.

8. Scott, I. R. Biochem. J. 1981, 194, 829-838.

9. Hanson, K. M.; Li, B.; Simon, J. D. J. Am. Chem. Soc. 1997, 119, 2715-2721.

10. Mohammad, T.; Morrison, H.; Hogenesch, H. "Invited Review Urocanic Acid Photochemistry and Photobiology" 1999, 69.

11. Using, A. T.; Weber, A.L. Orig Life Evol Biosph. 2005, 35, 421-422.

12. Plato, C. Anal. Chem. 1972, 44, 1531-1534.

13. Morales, J.; Günther, G.; Zanocco, A. L. Anal. Lett. 2012, 46, 37-41.

14. Good, W. D.; Smith, N. K. J. Chem. Eng. Data 1969, 14, 102-106.

15. Meija, J. et al. Pure Appl. Chem. 2016, 88, 265-291.

16. Washburn, E. W. Bur. Stand. J. Res. 1933, 10, 525-558.

17. Sabbah, R.; Xu-wu, A.; Chickos, J. S.; Planas Leitao, M. L.; Roux, M. V.; Torres, L. A. Thermochim. Acta 1999, 331, 93-204.

18. Höne, G.; Hemminger, H.; Flammersheim, H.-J. Differential Scanning Calorimetry An Introduction for Practitioners, 1st ed. New York, 1996.

19. Campos, J. B.; Martinez-Gómez, A. J.; Orozco-Guareno, E. Meas. Sci. Technol. 2019, 30, 1-14.

20. Prosen, E. J. "Combustion in a Bomb of Compounds Containing Carbon, Hydrogen, Oxygen, and Nitrogen," in Experimental Thermochemistry Measurement of Heats of Reaction 1956,1st ed. New York: Interscience Publishers Inc. 141.

21. CODATA J. Chem. Thermodyn. 1978, 10, 903-906. 